\title{
Not All Elementary School Teachers Are Scared of Math
}

\author{
Christina Artemenko ${ }^{1,2}$ (1) , Nicolas Masson ${ }^{3,4}$ (]) , Carrie Georges ${ }^{4}$ () , Hans-Christoph Nuerk ${ }^{1,2}$ (]) , \\ Krzysztof Cipora ${ }^{1,2,5}$
}

[1] Department of Psychology, University of Tuebingen, Tuebingen, Germany. [2] LEAD Graduate School \& Research Network, University of Tuebingen, Tuebingen, Germany. [3] Institut de Recherche en Sciences Psychologiques, Université catholique de Louvain, Louvain, Belgium. [4] Institute of Cognitive Science and Assessment (COSA), Department of Behavioural and Cognitive Sciences (DBCS), Faculty of Humanities, Education and Social Sciences (FHSE), University of Luxembourg, Luxembourg, Luxembourg. [5] Centre for Mathematical Cognition, Mathematics Education Centre, Loughborough University, Loughborough, United Kingdom.

Journal of Numerical Cognition, 2021, Vol. 7(3), 275-294, https://doi.org/10.5964/jnc.6063

Received: 2020-08-04 • Accepted: 2020-10-04 • Published (VoR): 2021-11-30

Handling Editor: Wim Fias, Ghent University, Ghent, Belgium

Corresponding Author: Christina Artemenko, Department of Psychology, University of Tuebingen, Schleichstr. 4, 72076 Tuebingen, Germany. E-mail: christina.artemenko@uni-tuebingen.de

Related: This article is part of the JNC Special Issue "Direct and Conceptual Replication in Numerical Cognition", Guest Editors: Mojtaba Soltanlou \& Krzysztof Cipora, Journal of Numerical Cognition, 7(3), https://doi.org/10.5964/jnc.v7i3

Supplementary Materials: Data, Materials [see Index of Supplementary Materials]

\begin{abstract}
Teachers are strong role models for their pupils, especially at the beginning of education. This also holds true for math: If teachers feel anxious about math, the consequences on the mathematical education of their pupils is detrimental. Previous studies have shown that (future) elementary school teachers have higher levels of math anxiety than most people studying other subjects. Here, we set out to conceptually replicate these findings (e.g., meta-analysis by Hembree, 1990, https://doi.org/10.2307/749455) by comparing math anxiety levels of pre-service and in-service German and Belgian elementary school teachers to a reference group of German university students from various fields of study. Moreover, we questioned this finding by asking which elementary school teachers experience math anxiety, considering gender, specialization, and experience, and investigated how math anxiety relates to teaching attitudes towards math. We replicated the previous finding by showing that female elementary school teachers have a higher level of math anxiety as compared to other female students. Importantly, female elementary school teachers without math specialization indeed had higher levels of math anxiety than female students from other fields and almost a quarter of them experience critical math anxiety. In contrast, female elementary school teachers with math specialization did not show an increased level of math anxiety as compared to the reference sample. Considering that not only these but all teachers, regardless of specialization, teach math in elementary school in the investigated educational systems, the math anxiety of elementary school teachers is a potential problem for their pupils' math attitudes and learning.
\end{abstract}

\section{Keywords}

math anxiety, elementary school teachers, teacher education, replication

Math anxiety-a negative emotional response to numbers and math tasks-is related to impaired math performance and achievement (Hembree, 1990; Ma, 1999; Namkung, Peng, \& Lin, 2019; Zhang, Zhao, \& Kong, 2019). A vicious cycle, that is, math anxiety and impaired math performance amplify each other, is one of the most plausible explanations for this link (e.g., Maloney, 2016). Several factors play a role in this mechanism: specific numeric difficulties, general cognitive 
deficits (e.g., limited working memory capacity), genetic influences, and social factors (e.g., teacher attitudes, gender stereotypes) (for reviews see Dowker, Sarkar, \& Looi, 2016; Maloney, 2016; Maloney \& Beilock, 2012; Suárez-Pellicioni, Núñez-Peña, \& Colomé, 2016). There is evidence that children develop math anxiety during the first years of formal math education, i.e., in elementary school (Ramirez, Gunderson, Levine, \& Beilock, 2013; Wu, Barth, Amin, Malcarne, \& Menon, 2012; see also Suárez-Pellicioni et al., 2016; but see Krinzinger, Kaufmann, \& Willmes, 2009). Therefore, it is important to understand the influence of contributing factors that children are exposed to at this stage.

Children learn math in elementary school, so their skills and attitudes towards math are particularly shaped in the school environment. During learning, elementary school teachers are strong role models for their pupils. In several educational systems, one teacher is in charge of teaching most of the subjects to their pupils in elementary school (grades 1 to 4/6). In such systems, the content being taught does not necessarily fully overlap with the teacher's own interests. In fact, individuals deciding on a career as an elementary school teacher very rarely decide on it because they wish to teach mathematics (Porsch, 2017). So, children might face elementary school teachers who have negative attitudes towards math or even experience elevated math anxiety.

A teacher's math anxiety can trigger student math anxiety (Hembree, 1990) and negatively affect math achievement (Beilock, Gunderson, Ramirez, \& Levine, 2010; Ramirez, Hooper, Kersting, Ferguson, \& Yeager, 2018; but see Hadley \& Dorward, 2011). Importantly, most elementary school teachers are female and therefore potentially stronger role models for girls. Thus, girls are more likely to adopt their female teachers' stereotypical beliefs (e.g., that boys but not girls are good at math). This can lead to lower math achievement within one school year at the beginning of elementary school (Beilock et al., 2010). This finding points towards the negative consequences of math anxiety for elementary school teachers and the need for further investigation.

Because of the consequences, it is a real problem when elementary school teachers actually have elevated math anxiety themselves (Wood, 1988). Unfortunately, several studies provide evidence that elementary school teachers have a high average level of math anxiety. For instance, in the meta-analysis by Hembree (1990), pre-service elementary school teachers had the highest level of math anxiety among students enrolled in different curricula (e.g., physical sciences, math/science, health sciences, business, social sciences, humanities). Similarly, Kelly and Tomhave (1985) reported that pre-service elementary school teachers as a group have the highest levels of math anxiety compared to other groups of students vulnerable to math anxiety (i.e., students who usually avoid math; except for the ones who were supposed to take part in a math anxiety workshop). The first basic aim of our study was to replicate the finding that elementary school teachers have more math anxiety than others.

In this respect it is important to note that not all studies have found pre-service elementary school teachers to have elevated math anxiety. It might be that because of different educational systems, the math anxiety of elementary school teachers might be on average lower in some countries (e.g., Turkey; Çatlioğlu, Birgin, Coştu, \& Gürbüz, 2009; Çatlioğlu, Gürbüz, \& Birgin, 2014; Uysal \& Dede, 2016) than in others (e.g., USA and Poland; Beilock et al., 2010; Hughes, Swars Auslander, Stinson, \& Fortner, 2019; Isiksal, Curran, Koc, \& Askun, 2009; Szczygieł \& Cipora, 2016). When comparing the average math anxiety scores of pre-service elementary teachers (mostly from the USA and Canada) that were assessed by the frequently used Mathematics Anxiety Rating Scale (MARS) to the originally provided normative data (Richardson \& Suinn, 1972), they belong to the $40^{\text {th }}$ percentile (Swars, Daane, \& Giesen, 2006), 50 ${ }^{\text {th }}$ percentile (Brady \& Bowd, 2005; Gresham, 2007; Vinson, 2001), 60 ${ }^{\text {th }}$ percentile (Hembree, 1990) or even $75^{\text {th }}$ percentile (Gresham, 2008; Kelly \& Tomhave, 1985). The data regarding in-service elementary school teachers is much scarcer (Beilock et al., 2010; Hughes et al., 2019). This indicates large discrepancies in the observed differences, as it shows that the math anxiety of pre-service and in-service elementary school teachers might not necessarily be as high in all educational systems as for those in the countries predominantly studied so far.

From a methodological perspective, there are no specified estimates of the prevalence of or cut-off criteria for math anxiety (cf. Cipora, Artemenko, \& Nuerk, 2019). At the same time, norms are not available for most math anxiety questionnaires or are available only in some languages or for some age groups (for examples of norms see Caviola, Primi, Chiesi, \& Mammarella, 2017; Cipora, Willmes, Szwarc, \& Nuerk, 2018). For this reason, direct group comparisons remain the most feasible method to check if elementary school teachers are characterized by elevated levels of math anxiety as compared to other groups. Therefore, the current study will use a reference group of students from other 
fields to evaluate the level of math anxiety of elementary school teachers from two western European countries, Germany and Belgium.

Taken together, there is evidence that elementary school teachers on average have relatively high levels of math anxiety. Nevertheless, it might be that elementary school teachers differ in terms of math anxiety regarding several factors. Here, we consider the factors gender, specialization, and experience, and further examine whether math anxiety may impact the teaching attitudes of elementary school teachers.

Gender. First, gender effects in terms of math anxiety may be of particular relevance to elementary school teachers because most of them are female. In general, math anxiety is usually higher in females than males (Hembree, 1990). This gender difference might be a reason for elevated math anxiety in elementary school teachers, because the majority of female teachers just might express more math anxiety driven by gender. However, the problem of math anxiety and elementary school teachers cannot be reduced to gender differences, because female pre-service elementary school teachers were found to express more math anxiety than female students from other fields (Szczygieł \& Cipora, 2016). For elementary school teachers in particular, some studies found gender differences (Brady \& Bowd, 2005; Kelly \& Tomhave, 1985) but others did not (Çatlioğlu et al., 2009, 2014; Rahayu, Mustadi, \& Sarjiman, 2019). Therefore, the question will be addressed, if female elementary school teachers have a higher level of math anxiety as compared to their male counterparts (Kelly \& Tomhave, 1985).

Specialization. Second, elementary school teachers follow various educational trajectories, in which they could either choose or avoid math specialization before teaching math in the classroom. Since math anxiety leads to math avoidance (Jaggernauth \& Jameson-Charles, 2015), math-anxious teachers might have avoided specializing in math during their education (Porsch, 2017). This is a problem especially for educational systems in which one teacher teaches almost all subjects, including math (instead of having specialized subject teachers), in elementary school. In several countries future teachers can select specific subjects at different stages of their education in which to specialize. For instance, German pre-service teachers who study elementary school education choose majors that may or may not include math. Similarly, French-speaking Belgian secondary school students can select their educational course to contain a high or low amount of math. The consequences might be that elementary school teachers differ in their levels of math anxiety and enjoyment of teaching math and these differences might relate to their own past educational choices (Porsch, 2017; for middle school teachers see also Malinsky, Ross, Pannells, \& McJunkin, 2006). Therefore, this study will differentiate between teachers who specialized in math or not during their education to investigate whether all elementary school teachers experience elevated math anxiety.

Experience. Third, the math anxiety of elementary school teachers might decrease with increasing experience in teaching math. This is supported by studies reporting that students have lower levels of math anxiety at the end, compared to students at the beginning, of studies in elementary school education (Çatlioğlu et al., 2009; Isiksal et al., 2009; but see Rahayu et al., 2019). However, the reported high levels of math anxiety are almost exclusively based on studies on pre-service elementary school teachers (Hembree, 1990; Kelly \& Tomhave, 1985). There is some evidence that in-service elementary school teachers might have reduced math anxiety due to their teaching experience, although math anxiety did not completely fade away (Gresham, 2018). Therefore, the current study will not only focus on pre-service elementary school teachers, who will become teachers in the future, but also on in-service elementary school teachers, who are already teaching math, so that we could investigate the role of experience.

Teaching attitudes. Finally, math anxiety might impact the teaching attitudes of elementary school teachers. Independent of whether or not math anxiety of teachers has a direct impact on their pupils' math achievement, it might still be accompanied by teaching anxiety or negative attitudes towards teaching math, which may affect teacher attitude and ultimately the quality of their math lessons (Hadley \& Dorward, 2011; Ramirez et al., 2018). Supporting evidence has shown that pre-service elementary school teachers with higher levels of math anxiety were less confident in teaching math (Brady \& Bowd, 2005; Bursal \& Paznokas, 2006). Pre-service and in-service elementary school teachers with higher levels of math anxiety were further observed to have lower math teacher efficacy in math and less math knowledge (Ganley, Schoen, LaVenia, \& Tazaz, 2019; Gresham, 2008; Jaggernauth \& Jameson-Charles, 2015; Swars et al., 2006). Taken together, higher math anxiety may be associated with lower teacher confidence and efficacy, which in turn might have a detrimental impact on student achievement in math during elementary school. 
The current study has two aims: The first aim is to conceptually replicate the finding of the meta-analysis by Hembree (1990) that math anxiety is higher for elementary school teachers than for students from other fields. The replication is relevant because the math anxiety of elementary school teachers has consequences for their pupils and it is necessary because previous studies have reported divergent levels of math anxiety, mostly lacked a reference sample, and almost exclusively were based on pre-service teachers. The second aim addresses whether all elementary school teachers experience math anxiety by the consideration of gender, specialization, and experience. Thereby, female elementary school teachers are expected to show higher math anxiety than males. Furthermore, math anxiety is expected to be lower for elementary school teachers who specialized in math during their studies. Due to experience, in-service teachers are expected to show less math anxiety than pre-service teachers. Finally, we expect a negative association of math anxiety with teaching attitudes towards math.

\section{Methods}

\section{Participants}

The samples of pre-service and in-service elementary school teachers consisted of German teachers and French-speaking Belgian teachers. The German teachers were recruited via internal e-mails within the Ludwigsburg University of Education, via e-mails of a school headmaster, and via personal contacts. The Belgian teachers were recruited via e-mails of professors of the elementary school education program to current and former students. After exclusion (see Table 1), the final samples consisted of 131 German teachers (116 female; age: $M=24.0, S D=5.89$, Range $=18-62$ years) and 127 Belgian teachers (107 female; age: $M=27.1, S D=10.00$, Range $=19-63$ years). The teacher samples included pre-service (German: $n=99$, Belgian: $n=76$ ) and in-service elementary school teachers (German: $n=32$; Belgian: $n=51$ ). For additional analyses, the German teachers were categorized by whether they specialized in mathematics during their teacher education $(n=75)$ or not $(n=56)$ and the Belgian teachers by whether they specialized in mathematics during their secondary school education $(n=78)$ or not $(n=49)$. Specialization in math means that German teachers studied math as a major when deciding between different subjects, and thus took additional math courses and math teaching courses. For Belgian teachers it means that they specialized in math during secondary school, where they received an educational curriculum that contained a high number of math classes. The proportion of students specializing in math in the German sample (57.25\%) approximately reflected the actual proportion of students specializing in math at the Ludwigsburg University of Education (47.97\%).

\section{Table 1}

Exclusion Criteria for the Samples of German and Belgian Elementary School Teachers and the Reference Sample of German University Students

\begin{tabular}{lccc}
\hline Sample & German Teachers & Belgian Teachers & Reference Sample \\
\hline Initial sample $(\boldsymbol{N})$ & 164 & 191 & 1049 \\
Exclusion criteria $(\boldsymbol{n})$ & & & \\
$\quad$ Not finished & 22 & 45 & 110 \\
$\quad$ Not eligible & 8 & 3 & 34 \\
Noisy environment & 0 & 12 & 36 \\
Dishonest responses & 0 & 0 & 4 \\
$\quad$ Duration $>30$ min & 3 & 4 & 17 \\
Final sample $(\boldsymbol{N})$ & 131 & 127 & 848 \\
\hline
\end{tabular}

As a reference sample, German university students who studied various subjects other than elementary school education were recruited via internal e-mail within the University of Tuebingen. In the recruiting e-mail, age of 18 years or above and German as native language were stated as inclusion criteria. After exclusion (see Table 1), the final sample consisted of 848 German students (597 female; age: $M=23.50, S D=4.17$, Range $=18-56$ years). 
Participants were consecutively excluded from the initial sample based on non-completion of the survey, ineligibility for the specific sample, very or extremely noisy environment during study completion, responding dishonestly, and for spending more than $30 \mathrm{~min}$ on the survey (because of a median completion duration of under $15 \mathrm{~min}$ ) (see Table 1, for similar exclusion criteria see also Cipora, Soltanlou, Reips, \& Nuerk, 2019). The eligibility for the teacher samples included being an elementary school teacher or studying elementary school education to become a teacher. The eligibility for the reference sample was conferred by German native speaker status, while teachers in elementary school were considered as having a language level (in German/French) high enough to respond to the survey.

All participants gave informed consent via mouse click and were offered to enter a raffle for vouchers upon completion. The study was approved by the Ethics Committee for Psychological Research of the University of Tuebingen.

\section{Materials}

Math anxiety was assessed by the abbreviated math anxiety scale (AMAS; Hopko, Mahadevan, Bare, \& Hunt, 2003). For the German translation, the items by Dietrich, Huber, Moeller, and Klein (2015) were slightly modified to whole sentences (as in the original English version). For the French-speaking Belgian sample, the AMAS items were translated into French from the original English version. Participants were asked to indicate how anxious they would feel in each math situation described in nine items using a 5-point Likert scale $(1=$ low anxiety, $5=$ high anxiety). The sum score was calculated, with higher values corresponding to higher math anxiety. The AMAS has two subscales: learning math anxiety and math evaluation anxiety (Hopko et al., 2003). Here, we focus on total AMAS scores and present the analyses considering the subscales in the Appendix (see Table A2 and Table A3).

The AMAS is characterized by adequate reliability and validity in the original English form as well as in several other language forms (Cipora, Szczygiel, Willmes, \& Nuerk, 2015; Hopko et al., 2003; Primi, Busdraghi, Tomasetto, Morsanyi, \& Chiesi, 2014; Vahedi \& Farrokhi, 2011). The original English form had an internal consistency of $\alpha=.90$ and a test-retest reliability of $r_{t t}=.85$ (Hopko et al., 2003). Reliability of the AMAS in its German form (Cronbach's alpha: .89) as well as in its French form (Cronbach's alpha: .91) in the current samples can be considered as very good. As proposed by Cipora et al. (2015) in the case of AMAS, ordinal alpha, based on polychoric correlations, is a more suitable method for estimating reliability. Using this measure, AMAS reliability was even slightly higher (ordinal alpha of the German form: .93; ordinal alpha of the French form: .91), which is comparable to the ordinal alpha reported for AMAS administered online (Polish form: 0.88; Cipora et al., 2018).

For teachers only, the enjoyment of teaching math ("I like teaching math.") and the ease of teaching math ("Teaching math is easy for me.") were assessed on a 5-point Likert scale ( 1 = not at all, 5 = absolutely; additional option: not yet taught). These items were originally formulated in German for the purpose of this study. The translation of the survey (including teacher-related items, demographic items, quality items, and instructions) into French was conducted by a German-French bilingual individual. The material for assessing math anxiety and teaching attitudes can be found in the Open Material.

\section{Procedure}

The study was conducted as an online survey on the SoSci Survey platform (Leiner, 2014). In contrast to laboratory studies, the environment during participation in online surveys is less controllable. Therefore, it is recommended to use quality items (Reips, 2002). Here, after completion of the study we asked how noisy the participants' environment was during survey completion on a 6-point Likert scale $(1=$ silent, $2=$ very quiet, $3=$ fairly quiet, $4=$ fairly noisy, $5=$ very noisy, 6 = extremely noisy) and whether the survey was completed honestly (yes or no). As this study was part of a larger project, additionally to the assessment of math anxiety and teaching attitudes, several other questionnaires, and a math performance task (administered after anxiety- and math-related questionnaires but before additional measures and teacher-related items) were included. All of these measures are outside of the scope of this paper. Note that participants were notified at the beginning of their participation in the study that they would have to complete a mathematical performance task. The median completion duration was $11 \mathrm{~min}$ for German teachers, $13 \mathrm{~min}$ for Belgian teachers, and 9 min for the reference sample (survey was shorter as it did not include teacher-related items). 


\section{Analysis}

Data were statistically analyzed using jamovi (The jamovi project, Version 1.1, 2019) based on R (R Core Team, 2018) and JASP (Jeffreys's Amazing Statistics Program, Version 0.13.1, JASP Team, 2016). For statistical data analysis, frequentist as well as Bayesian approaches (if possible) were applied to complement classical analyses with information on how likely there was evidence for an effect or evidence for a null effect. The Bayes factor $(B F)$ is defined as how much more likely the observed data is under one compared to the other hypothesis. Thereby, $B F_{10}$ means a Bayes factor in favor of the alternative hypothesis (evidence for a difference when $B F_{10}>1$ ) and $B F_{01}$ means a Bayes factor in favor of the null hypothesis (evidence for no difference when $B F_{01}>1$ ), whereby $B F_{01}=1 / B F_{10}$ (Faulkenberry, Ly, \& Wagenmakers, 2020). $A B F$ between 1 and 3 indicates anecdotal evidence, a $B F$ between 3 and 10 moderate evidence, a $B F$ between 10 and 30 strong evidence, a $B F$ between 30 and 100 very strong evidence, and a $B F$ above 100 extreme evidence in favor of one hypothesis (Jeffreys, 1961; Lee \& Wagenmakers, 2013).

\section{Results}

Our samples of elementary school teachers included a low proportion of males (13.57\%). This was not a problem of sampling, but rather reflects the fact that the vast majority of elementary school teachers in both countries are female. While this is a real-life problem, unfortunately the power for statistical analysis would be too low when considering gender as an additional factor ( $n<10$ for some cells). On the other hand, gender cannot be ignored because of the extreme evidence for gender differences in math anxiety in the literature (Hembree, 1990) as well as in the current sample, $t(256)=4.16, p<.001, d=0.76, B F_{10}>100$, with higher math anxiety for female $(M=20.85, S D=7.25)$ than male elementary school teachers $(M=15.54, S D=5.29)$. Therefore, we decided to run the statistical analysis on female teachers only (which represent the vast majority of elementary school teachers). For a full overview, we provided descriptive data for male teachers in the Appendix (Table A1).

Since teacher data were collected in Germany and in Belgium, we tested whether these samples differed regarding math anxiety. There was no significant difference in math anxiety between the female German teachers $(M=20.66, S D=$ 6.72) and the female Belgian teachers $(M=21.06, S D=7.81), t(221)=0.40, p=.687$. There was moderate evidence that they did not differ, $B F_{01}=6.33$. Therefore, these samples were analyzed together.

\section{Math Anxiety}

An independent samples $t$-test was performed to compare math anxiety between female teachers and the reference sample of female students. Math anxiety was significantly higher in female teachers compared to the reference sample, $t(818)=2.28, p=.023, d=0.18, B F_{10}=1.11$ (see Figure $1 \mathrm{~A}$, Table 2; for the subscales learning math anxiety and math evaluation anxiety see the Appendix, Table A2). As indicated by the Bayes Factor of about one, the evidence for this difference was only anecdotal and, in fact, the data were inconclusive, as the data are equally likely to occur under the alternative hypothesis and the null hypothesis.

To examine if math anxiety differs between different groups of teachers, an ANOVA was conducted with the between-subject factors specialization (math or not) and experience (pre-service or in-service) (for the separate results for the subscales of math anxiety see the Appendix, Table A3, and for the separate results for the German and Belgian teachers see the Appendix, Table A4). The main effect of specialization was significant, $F(1,219)=16.40, p<.001, \eta_{p}^{2}$ $=.07$, indicating that math anxiety was higher in female teachers without math specialization as compared to female teachers with math specialization (see Figure 2, see Table 3 for results of the Bayesian ANOVA). The main effect of experience, $F(1,219)=0.06, p=.812$, and the interaction between specialization and experience were not significant, $F(1,219)=0.01, p=.916$. The Bayesian ANOVA provided convergent evidence that specialization is the only factor that ought to be considered and moderate evidence for a null effect of experience. 
Table 2

Descriptive Data for Female Elementary School Teachers' Math Anxiety and Teaching Attitudes

\begin{tabular}{|c|c|c|c|c|c|}
\hline Group & & & $N$ & $M$ & $S D$ \\
\hline \multicolumn{6}{|c|}{ Math Anxiety } \\
\hline \multicolumn{6}{|l|}{ Teachers } \\
\hline Yes & & & 223 & 20.85 & 7.25 \\
\hline No & & & 597 & 19.65 & 6.51 \\
\hline \multicolumn{6}{|c|}{ Math Anxiety of Teachers } \\
\hline \multicolumn{6}{|l|}{ Specialization } \\
\hline \multirow[t]{2}{*}{ Yes } & Experience & Pre-service & 91 & 18.99 & 6.47 \\
\hline & & In-service & 38 & 19.13 & 6.83 \\
\hline \multirow[t]{2}{*}{ No } & Experience & Pre-service & 72 & 23.26 & 7.42 \\
\hline & & In-service & 22 & 23.64 & 7.71 \\
\hline \multicolumn{6}{|c|}{ Enjoyment of Teaching Math ${ }^{a}$} \\
\hline \multicolumn{6}{|l|}{ Specialization } \\
\hline Yes & & & 116 & 4.45 & 0.75 \\
\hline No & & & 66 & 3.71 & 1.08 \\
\hline \multicolumn{6}{|l|}{ Experience } \\
\hline Pre-service & & & 127 & 4.19 & 0.95 \\
\hline In-service & & & 55 & 4.16 & 0.96 \\
\hline \multicolumn{6}{|c|}{ Ease of Teaching Math ${ }^{a}$} \\
\hline \multicolumn{6}{|l|}{ Specialization } \\
\hline Yes & & & 115 & 4.05 & 0.78 \\
\hline No & & & 66 & 3.42 & 0.95 \\
\hline \multicolumn{6}{|l|}{ Experience } \\
\hline Pre-service & & & 126 & 3.76 & 0.90 \\
\hline In-service & & & 55 & 3.96 & 0.88 \\
\hline
\end{tabular}

${ }^{a}$ For the analyses of teaching attitudes, elementary school teachers who selected the option "not yet taught" were excluded ( $n=41$ for enjoyment; $n=42$ for ease).

To further explore the missing effect of experience on math anxiety, experience level (in years) was considered for female in-service teachers $(N=59, M=10.19, S D=10.44, M d n=5$, Range $=0.5-38$ years). The Pearson correlation between experience level and math anxiety was not significant, $r(57)=-.063, p=.637$. Note that similar data for pre-service teachers (e.g., years of teacher education) was not assessed in the current study.

Because of the significant effect of specialization on math anxiety, the female teachers were further compared to the reference sample of female students dependent on specialization by independent samples $t$-tests. Female teachers without specialization in math showed higher levels of math anxiety in comparison to the reference sample, $t(689)=$ $5.02, p<.001, d=0.56, B F_{10}>100$. In contrast, female teachers with specialization in math did not significantly differ from the reference sample, $t(724)=0.98, p=.328, B F_{10}=0.17$, and there was moderate evidence that they did not differ, $B F_{01}=5.85$ (see Figure 1B). 


\section{Figure 1}

Math Anxiety of Female Teachers Compared to the Reference Sample of Students From Other Fields, and Math Anxiety of Female Teachers Depending on Specialization (Math or Not)

A

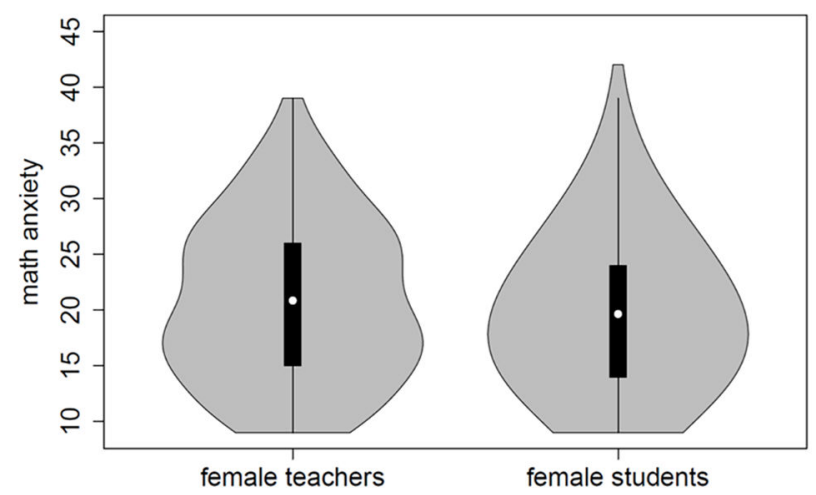

B

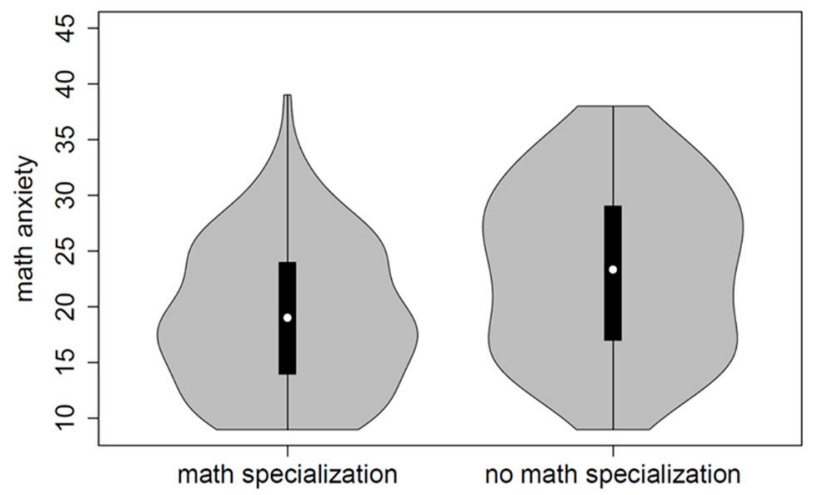

Note. White dots indicate the mean, boxes indicate the interquartile range (IQR $=25-75 \%$ ), and gray zones indicate the distribution (kernel density estimation).

Table 3

Statistical Results for Math Anxiety of Female Elementary School Teachers (Bayesian ANOVA)

\begin{tabular}{|c|c|c|c|c|c|}
\hline Models & $P(M)$ & $P(M /$ data $)$ & $B F_{M}$ & $B F_{10}$ & Error \% \\
\hline Null model & 0.2 & 0.00 & 0.00 & 1.00 & \\
\hline Specialization & 0.2 & 0.83 & 19.59 & $>100$ & 0.00 \\
\hline Specialization + experience & 0.2 & 0.14 & 0.64 & $>100$ & 0.91 \\
\hline Specialization + experience + interaction & 0.2 & 0.03 & 0.13 & 80.23 & 1.30 \\
\hline Experience & 0.2 & 0.00 & 0.00 & 0.16 & 0.00 \\
\hline Effects & $P($ incl $)$ & $P($ incl $/$ data $)$ & $B F_{i n c l}$ & $B F_{\text {excl }}$ & \\
\hline Specialization & 0.4 & 0.97 & $>100$ & 0.00 & \\
\hline Experience & 0.4 & 0.14 & 0.17 & 6.22 & \\
\hline Interaction specialization $\times$ experience & 0.2 & 0.03 & 0.23 & 4.22 & \\
\hline
\end{tabular}

Note. The effect-based analyses (lower part of the table) compares models that contain the effect to equivalent models stripped of the effect (analysis suggested by Sebastiaan Mathôt). 


\section{Figure 2}

Math Anxiety of Female Teachers Depending on Specialization (Math or Not) and Experience (Pre-Service or In-Service)

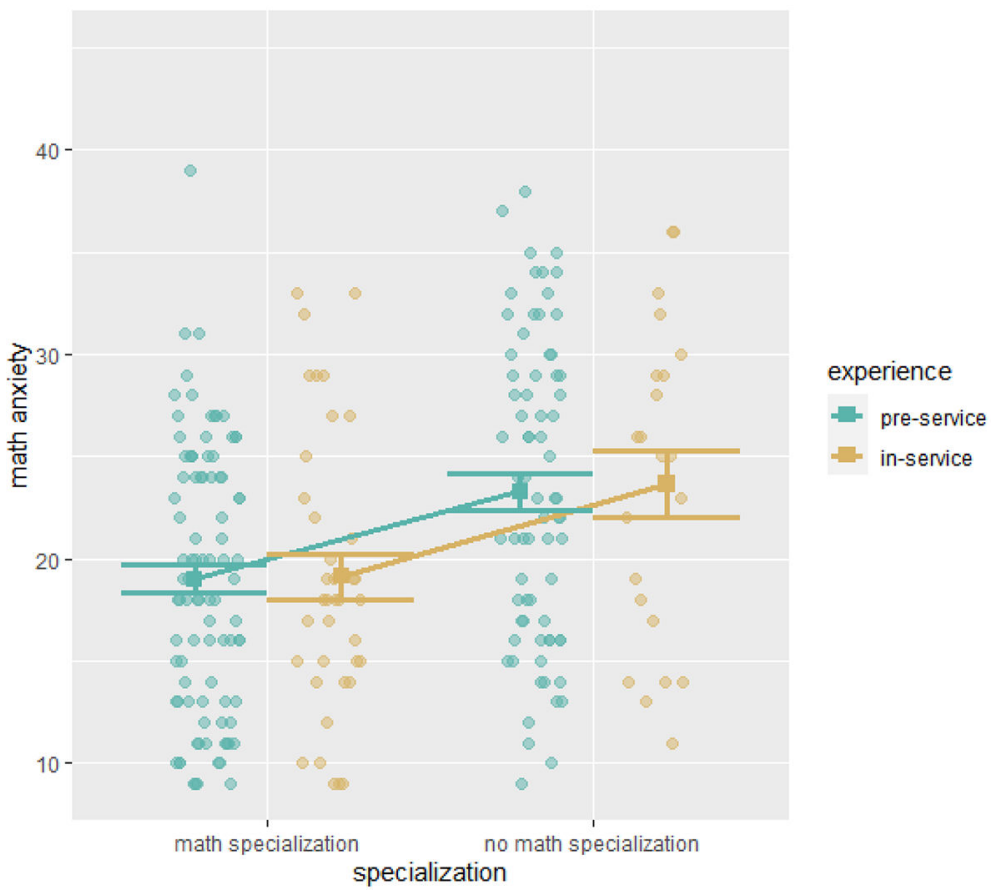

Note. Error bars indicate $S E$.

To further evaluate the math anxiety of teachers and the moderating effect of math specialization, we estimated the distribution of math anxiety in female elementary school teachers in relation to the reference sample of female students. Due to the lack of diagnostic criteria for math anxiety (Cipora, Artemenko, et al., 2019), we followed the suggestions for diagnosing dyscalculia (cut-off: dyscalculia $\leq 10^{\text {th }}$ percentile; math anxiety $>90^{\text {th }}$ percentile) or being at risk for dyscalculia (cut-off: dyscalculia $\leq 25^{\text {th }}$ percentile; math anxiety $>75^{\text {th }}$ percentile) in relation to normative data (reference sample) (Kaufmann et al., 2009; Moeller, Fischer, Cress, \& Nuerk, 2012). This analysis shows that $12.56 \%$ of female teachers in our sample experience critical math anxiety and $33.63 \%$ at least are at risk for critical math anxiety (see Table 4). When considering specialization in math, only $4.65 \%$ of female teachers with math specialization experience critical math anxiety (24.03\% are at least at risk), but $23.40 \%$ of female teachers without math specialization experience critical math anxiety ( $46.81 \%$ are at least at risk).

Table 4

Distribution of Math Anxiety in Female Elementary School Teachers (Median, Quartiles, $10^{\text {th }}$ and $90^{\text {th }}$ Percentile of the Female Reference Sample)

\begin{tabular}{|c|c|c|c|c|c|}
\hline Percentile & $10 \%$ & $25 \%$ & $50 \%$ & $75 \%$ & $90 \%$ \\
\hline Norms & 11 & 13 & 18 & 23 & 28 \\
\hline \multicolumn{6}{|l|}{ Teachers } \\
\hline All & $86.55 \%$ & $77.58 \%$ & $52.02 \%$ & $33.63 \%$ & $12.56 \%$ \\
\hline Math specialization & $80.62 \%$ & $72.09 \%$ & $43.41 \%$ & $24.03 \%$ & $4.65 \%$ \\
\hline No math specialization & $94.68 \%$ & $85.11 \%$ & $63.83 \%$ & $46.81 \%$ & $23.40 \%$ \\
\hline
\end{tabular}

Note. The proportion of female teachers scoring above the given percentile norm of math anxiety was reported. The given percentiles include the $10^{\text {th }}$ percentile (10\%), lower quarter $(25 \%)$, median (50\%), upper quarter $(75 \%)$ indicating risk for critical math anxiety, and $90^{\text {th }}$ percentile $(90 \%)$ indicating critical math anxiety. The given norms depict the AMAS scores that correspond to the percentile based on the distribution of AMAS scores in the reference sample of female German University students $(N=848)$. 


\section{Teaching Attitudes}

The relation of math anxiety to enjoyment and ease of teaching math for female teachers was analyzed by Pearson correlations. Significant negative correlations of math anxiety were found for both enjoyment, $r(180)=-.470, p<.001$, and ease of teaching math, $r(179)=-.479, p<.001$, indicating that higher levels of math anxiety were associated with lower enjoyment and less ease in teaching math. The relation between enjoyment and ease was analyzed by polychoric correlations, which can be considered more suitable for single items with ordinal scales than Pearson correlations (see Hohol, Woloszyn, Nuerk, \& Cipora, 2018). Enjoyment and ease of teaching math were highly correlated, $r(179)=.730, p$ $<.001$.

To detect the factors that might influence the teaching attitudes of female elementary school teachers, ordinal logistic regressions were performed with the predictors math anxiety, specialization, and experience (for the separate results of German and Belgian teachers see the Appendix, Table A5). For enjoyment of teaching math, AIC $=393.10$, $\mathrm{BIC}=415.53, R_{M c F}^{2}=.13$, and for ease of teaching math, $\mathrm{AIC}=414.73, \mathrm{BIC}=437.12, R_{M c F}^{2}=.13$, the predictors math anxiety and specialization, but not experience, were significant (see Table 5). This indicates that on the one hand, with increasing math anxiety female elementary school teachers enjoyed teaching math less and found it more difficult to teach math, and on the other hand, female teachers with specialization in math showed higher levels of enjoyment and ease in teaching math than teachers without math specialization (see Figure 3).

To further explore the missing effect of experience, the relation between experience level (in years) and teaching attitudes was analyzed by Pearson correlations for female in-service teachers. Experience level did not significantly correlate with enjoyment of teaching, $r(52)=.011, p=.935$, or ease of teaching math, $r(52)=.059, p=.674$.

\section{Table 5}

Statistical Results for Teaching Attitudes of Female Elementary School Teachers (Ordinal Logistic Regression)

\begin{tabular}{llcrrrrr}
\hline Predictor & Reference category & Estimate & $\boldsymbol{S E}$ & $\boldsymbol{Z}$ & $\boldsymbol{p}$ & Odds Ratio [95\% CI] \\
\hline $\begin{array}{l}\text { Enjoyment of Teaching Math } \\
\quad\end{array}$ & & & & & & & \\
$\quad$ Math anxiety & & -0.12 & 0.02 & -5.51 & $<.001$ & 0.89 & {$[0.85,0.92]$} \\
$\quad$ Specialization & Yes & 1.17 & 0.32 & 3.70 & $<.001$ & 3.21 & {$[1.74,5.99]$} \\
$\quad$ Experience & In-service & -0.14 & 0.32 & -0.44 & .663 & 0.87 & {$[0.47,1.63]$} \\
\hline Ease of Teaching Math & & & & & & \\
$\quad$ Math anxiety & & -0.12 & 0.02 & -5.65 & $<.001$ & 0.88 & {$[0.85,0.92]$} \\
$\quad$ Specialization & Yes & 1.06 & 0.32 & 3.34 & $<.001$ & 2.90 & {$[1.56,5.45]$} \\
$\quad$ Experience & In-service & 0.41 & 0.31 & 1.31 & .189 & 1.51 & {$[0.82,2.80]$} \\
\hline
\end{tabular}




\section{Figure 3}

Teaching Attitudes of Elementary School Teachers (Enjoyment and Ease of Teaching Math) Depending on Specialization (Math or Not) and Experience (PreService or In-Service)

A

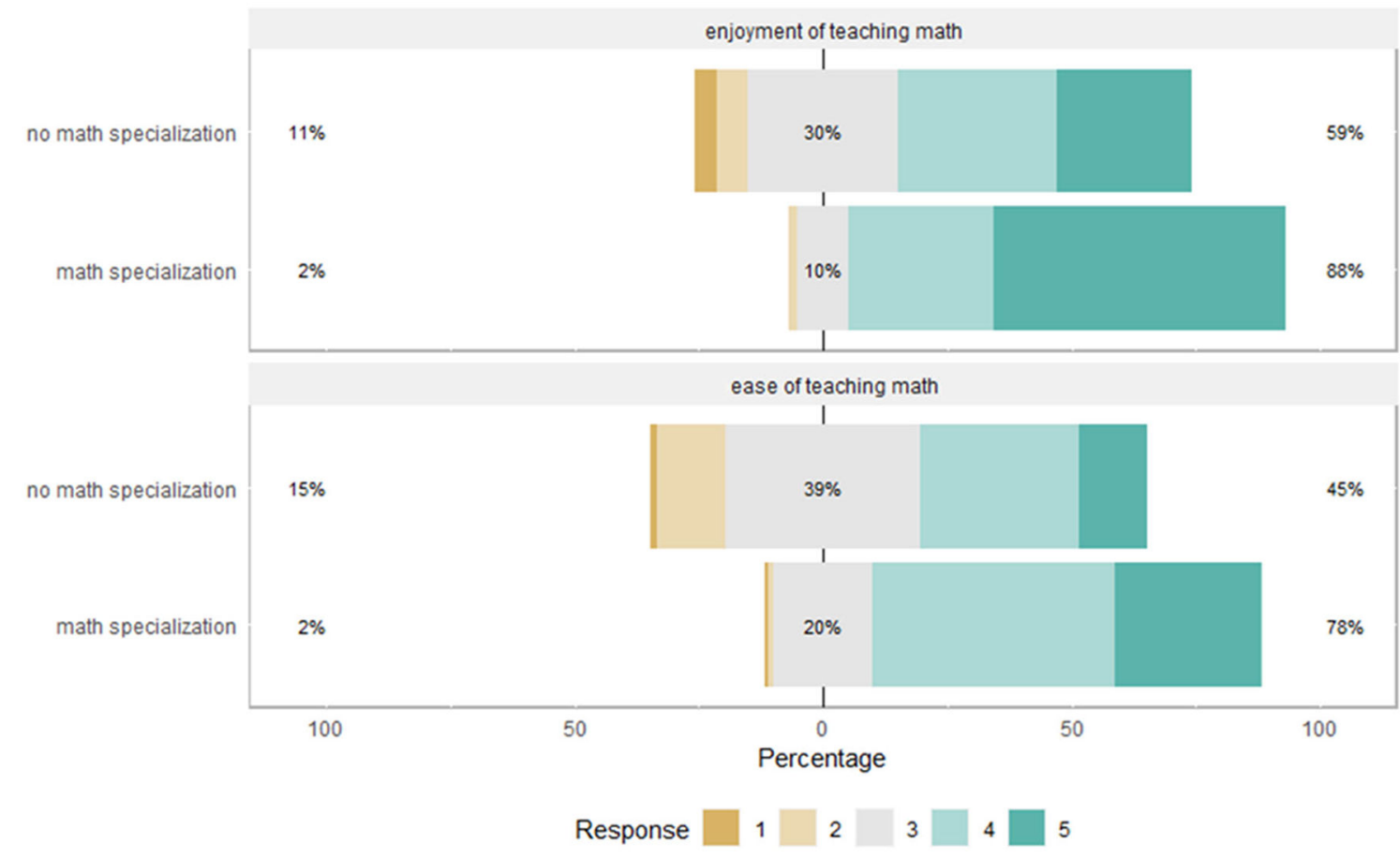

B

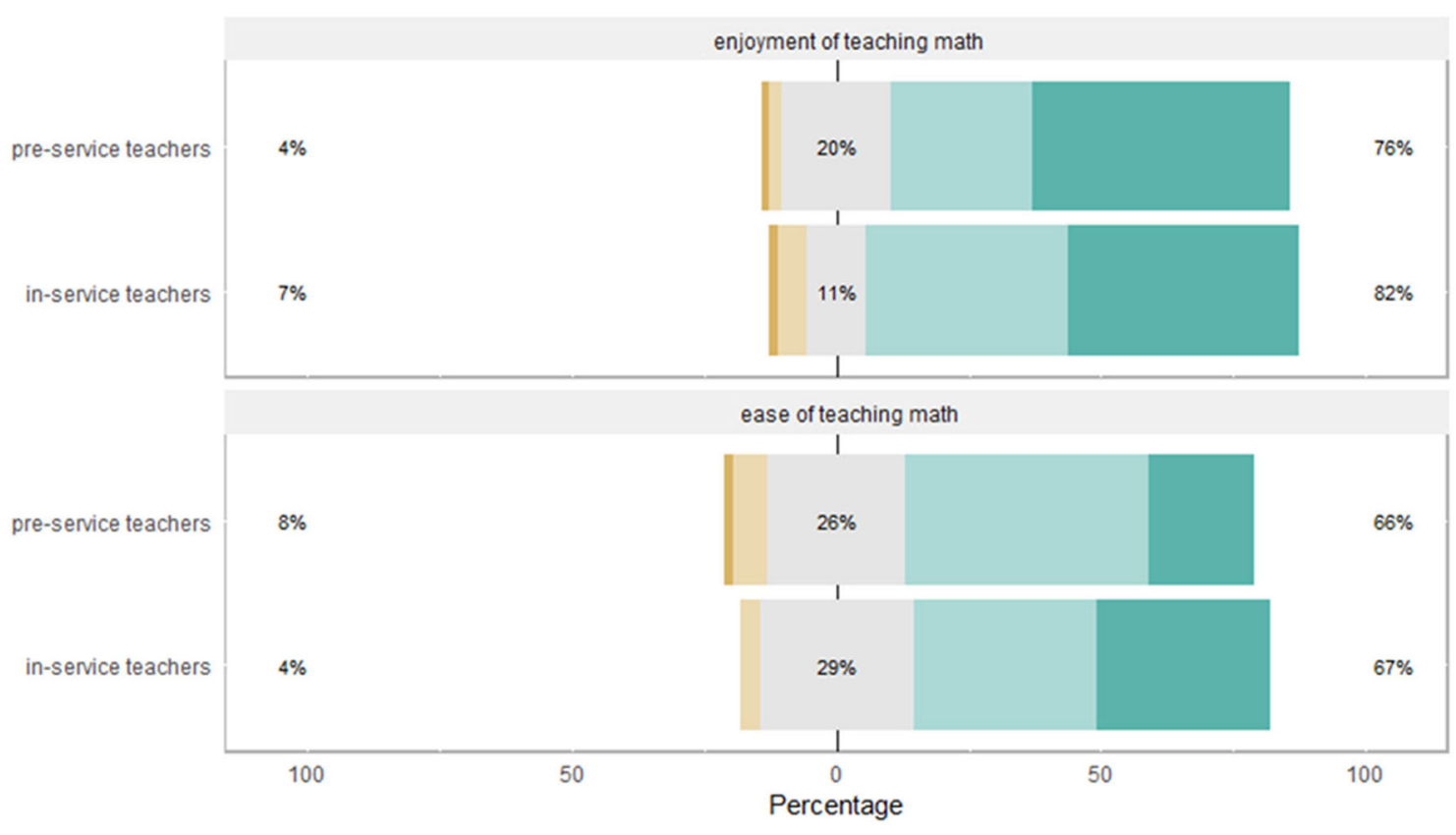

\begin{tabular}{l|l|l|l|l|l|l|} 
Response & & 1 & 2 & 3 & 4 & 5
\end{tabular} 


\section{Discussion}

The current study investigated math anxiety of elementary school teachers to replicate the higher levels of math anxiety found for teachers as compared to a reference sample, to identify which teachers are affected, and to disclose how math anxiety relates to their teaching attitudes. First, we replicated the finding that elementary school teachers have higher levels of math anxiety than students from other fields (Hembree, 1990; Kelly \& Tomhave, 1985). Secondly, math anxiety differed between teachers depending on specialization but not experience. Additionally, math anxiety differed between female and male teachers. Third, higher levels of math anxiety were associated with less enjoyment and ease of teaching math. These findings suggest that although elementary school teachers have on average more math anxiety than others, not all of them are equally affected and express negative attitudes towards teaching math. Treating elementary school teachers as a homogenous group (as most studies do) fails to consider the systematic heterogeneity we observed within this group.

The current study replicated the finding that female elementary school teachers have a higher level of math anxiety in relation to female students from other fields (Hembree, 1990; Kelly \& Tomhave, 1985; Szczygieł \& Cipora, 2016). On average, math anxiety was higher in pre-service and in-service female elementary school teachers as compared to female university students from various fields ranging from the sciences to the humanities. Interestingly, this effect was driven by learning math anxiety (rather than by math evaluation anxiety, see Appendix, Table A2), an AMAS subscale that is only sensitive to high levels of math anxiety (Cipora et al., 2018). Despite usually showing floor effects, learning math anxiety here differentiated between teachers and others. However, the overall effect size observed was small and evidence from Bayesian analysis was almost perfectly inconclusive. Even though our finding is in contrast to the relatively low levels of math anxiety found in pre-service Turkish elementary school teachers (Çatlioğlu et al., 2009, 2014; Isiksal et al., 2009; Uysal \& Dede, 2016), this replication is in line with the relatively high levels of math anxiety reported for pre-service elementary school teachers in the USA (Beilock et al., 2010; Hughes, 2016; Kelly \& Tomhave, 1985) and Poland (Szczygieł \& Cipora, 2016). Therefore, our results provided some evidence for a generalization of relatively higher levels of math anxiety to pre-service and in-service elementary school teachers in European countries like Germany and Belgium. However, a closer look at the results provides a more nuanced picture.

Female teachers who specialized in math essentially differed in math anxiety from female teachers who did not specialize in math. As expected, math anxiety was lower both in German teachers majoring in math compared to those not majoring in math during their studies of elementary school education (Ganley et al., 2019; Malinsky et al., 2006; Porsch, 2017) and in Belgian teachers who specialized in math during secondary school compared to those who chose an educational trajectory containing less math (see the Appendix, Table A4). This suggests that math anxiety plays a role in the selection of study foci and leads (future) elementary school teachers to avoid math (Jaggernauth \& Jameson-Charles, 2015; Porsch, 2017), or specialization in math mitigates math anxiety. This is in line with previous literature reporting math avoidance as one of the consequences of math anxiety in general (Ashcraft, 2002). Interestingly, the female teachers with specialization in math did not differ in math anxiety from female students from other fields, whereas we found extreme evidence that female teachers without specialization in math had more math anxiety than female students from other fields ranging from the sciences to the humanities. This was supported by the prevalence of critical math anxiety being only half as large for female teachers with math specialization (about a quarter being at risk), but more than twice as large for female teachers without math specialization (almost half are at risk) as compared to female reference norms. This shows that not all elementary school teachers have relatively high levels of math anxiety, but rather only those teachers who did not specialize in math during their studies or during school. This is of importance, because about half of elementary school teachers do not specialize in math and the strong effect of specialization is superior to the inconclusive evidence on the elevated math anxiety of elementary school teachers in general.

With increased experience in studying elementary school education, the math anxiety of pre-service elementary school teachers was found to decrease in previous studies (Çatlioğlu et al., 2009; Isiksal et al., 2009; but see Rahayu et al., 2019). Consistent with this reported decrease in math anxiety during teacher education, Gresham (2018) found evidence for a further decrease in math anxiety when teachers start teaching. Our study, however, does not support these previously found differences and instead provides moderate evidence for similar levels of math anxiety for female pre-service and in-service elementary school teachers, even when specialization in math was taken into account. Thus, 
our results suggest that math anxiety might not fade away (or build up) with increasing teaching experience. Thus, it might not matter how much experience the teachers have, but which experience they have (e.g., the grade and the respective complexity of math they typically teach). Given these contrary findings and our very limited knowledge about the math anxiety of in-service teachers, well-founded conclusions cannot be drawn at this moment and future studies on this topic are recommended.

Among elementary school teachers, female teachers were found to express more math anxiety than male teachers. This corroborates gender effects on math anxiety in general (Hembree, 1990) as well as in particular for elementary school teachers (Brady \& Bowd, 2005; Kelly \& Tomhave, 1985). While gender differences in math anxiety were found for elementary school teachers in Western countries (Brady \& Bowd, 2005; Kelly \& Tomhave, 1985), they were not found in other countries (Çatlioğlu et al., 2009, 2014; Peker \& Ertekin, 2011; Rahayu et al., 2019). Although this suggests cultural differences, further cross-cultural research is needed to support this claim. Nevertheless, all of these studies point to female teachers as the majority in elementary school education, highlighting the relevance of gender effects on math anxiety.

For elementary school teachers, math anxiety relates to teaching attitudes towards math. Higher levels of math anxiety were associated with lower enjoyment and ease of teaching math. This means that female teachers with increasing levels of math anxiety were less likely to enjoy, and more likely to be afraid of, teaching math, and also found teaching math difficult and considered themselves as being less confident in teaching math. Given that the teaching attitudes were assessed only by single items and after math anxiety and performance in the current study, the results should be treated with considerable caution due to possible biases (e.g., teachers reporting their teaching attitudes more consistently to their math anxiety). Nevertheless, our results were consistent with previous studies showing the relation of math anxiety to confidence (Brady \& Bowd, 2005; Bursal \& Paznokas, 2006), efficacy (Gresham, 2008; Jaggernauth \& Jameson-Charles, 2015; Swars et al., 2006) and anxiety of teaching math (Ganley et al., 2019; Olson \& Stoehr, 2019). For future research, psychometrically validated instruments are recommended for assessing teaching attitudes and teaching anxiety towards math (e.g., Ganley et al., 2019; Hunt \& Sari, 2019; Peker \& Ertekin, 2011).

Like math anxiety, teaching attitudes were found to differ depending on specialization, but not on experience. Female teachers with math specialization considered teaching math more enjoyable and easier than those without this specialization (Porsch, 2017). This could be explained by two processes, which are not necessarily mutually exclusive. First, it could reflect a matter of selection, meaning that students with negative teaching attitudes towards math do not want to specialize in math. Second, it could reflect an effect of studying math itself so that the knowledge and expertise gained by teachers specialized in math makes them feel more competent in teaching math. Both processes might explain our finding that specializing in math is related to better math teaching attitudes. However, in contrast to previous data (Hunt \& Sari, 2019), our results provided no evidence of a beneficial effect of teaching math on the teachers' attitudes, because female in-service and pre-service elementary school teachers did not significantly differ in enjoyment and ease of teaching math, and experience level in female in-service teachers did not significantly alter their teaching attitudes. As an open question, the different teaching experience regarding the grade and complexity of math might be addressed in future research. Taken together, studying math predicts better teaching attitudes towards math but teaching math does not.

There are several implications for educational practice of the presented research on math anxiety of elementary school teachers. Although not all elementary school teachers have high levels of math anxiety, the relatively high levels of math anxiety of teachers without specialization in math are critical, because all teachers-including these teachers-are supposed to teach math in elementary school in the investigated educational systems. So, math anxiety of teachers is a problem in this situation (Porsch, 2017; Wood, 1988), at least for educational systems like those in Germany (selection of majors during elementary school teacher education) or French-speaking Belgium (specialization during secondary school), and thus, math anxiety of teachers might lead to lower student achievement in math (Beilock et al., 2010). In order to prevent such detrimental consequences, Porsch (2017) recommends either changing elementary school education (i.e., education in schools should be based on the principle of subject teachers like in China rather than on the principle of class teachers so that not all (future) teachers are forced to learn and teach math) or changing elementary teacher education (i.e., education of teachers should support (future) teachers in dealing with their math anxiety and impart math knowledge so that they can learn to teach math). To deal with the math anxiety problem of elementary 
school teachers, some previously applied intervention approaches seemed to be successful in reducing math anxiety: For example, pre-service elementary school teachers showed reduced levels of math anxiety after a math methods course with teaching practice (however, there is a control group missing in the evaluation) (Gresham, 2007; Harper \& Daane, 1998; Sloan, 2010; Vinson, 2001) or after expanded microteaching as compared to a control group (Peker, 2009). Other intervention approaches targeting the consequences on students might be considered, such as decreasing gender stereotype endorsement by female teachers, increasing confidence and competence of teaching math, or offering coping strategies for math anxiety for teachers. In sum, whenever elementary school teachers are afraid of math-and math anxiety does not motivate them, leading to positive consequences (Wang et al., 2015)-there is a need for action to diminish the detrimental consequences for their students.

Although we believe that this research offers important implications, we acknowledge that the current study has some limitations. First, because most elementary school teachers are female, the current sample of male teachers was too small to be analyzed. Our results based on female teachers cannot be generalized to male teachers because of gender differences and thus future studies with a sufficient number of male elementary school teachers might focus on this issue. Second, the observational approach of this study does not allow for causal inferences. For instance, it is not clear whether math-anxious students just do not specialize in math to avoid it (Jaggernauth \& Jameson-Charles, 2015; Porsch, 2017) or if studying math increases real or perceived math competence and thereby decreases math anxiety and improves teaching attitudes. Third, implications for the consequences of the math anxiety of teachers on their students (Beilock et al., 2010; Ramirez et al., 2018) were derived from the literature, but they were not directly assessed in the current study. Fourth, the conclusions derived by the data of German and Belgian elementary school teachers might not be generalizable to other cultures, countries, and educational systems because of previously observed differences (Isiksal et al., 2009). Finally, this was an online study. Although the instrument AMAS for assessing math anxiety was proven to be equivalent either by online or paper-pencil administration (Cipora et al., 2018), any online study lacks the control usually obtained in laboratory studies. However, this format allowed for enough power to investigate within-group differences in elementary school teachers, which have often been neglected so far.

In conclusion, this replication study confirmed the fact that elementary school teachers are more affected by math anxiety as compared to students from other fields. However, not all teachers were found to have higher levels of math anxiety. For instance, female teachers without specialization in math had more math anxiety and less positive teaching attitudes than female teachers with specialization in math. In fact, almost half of these teachers could be classified as at risk for critical math anxiety, and almost a quarter as critically math anxious. Importantly, all elementary school teachers in these educational systems are obliged to teach math. Since teachers with high math anxiety might impact the math achievement of their students, this may pose a substantial problem for math education. Therefore, our work stresses the need for changes in teacher education to support elementary school teachers who did not specialize in math to cope with their anxiety not only for their own well-being, but also to prevent negative consequences on the emotions, attitudes, and future achievements of their students.

Funding: CA, KC, and HCN are members of the LEAD Graduate School \& Research Network [GSC1028], and NM was supported by a fellowship of Teach@Tuebingen, both of which are funded within the framework of the Excellence Initiative of the German federal and state governments. NM was further funded by grants from the National Research Fund of Luxembourg (FNR, Luxembourg) [FNR-INTER/FNRS/17/1178524] and from the Fonds National de la Recherche Scientifique (FRS-FNRS, Belgium) [PDR-T.0047.18]

Acknowledgments: We would like to thank Anita Kaiser, Joachim Engel, Stefan Smaczny, Laura Gottwald, and Ida Johanna M. L. C. von Lehsten for data collection, Maximilian Kenzo Molitor for support in figures and Zoë Kirste for language proofreading of the manuscript.

Competing Interests: Krzysztof Cipora is one of the Guest Editors of this Special Issue but played no editorial role in this particular article or intervened in any form in the peer review process.

Data Availability: For this article, a dataset is freely available (Artemenko, Masson, Georges, Nuerk, \& Cipora, 2021) 


\section{Supplementary Materials}

Raw data, analysis scripts, and material can be found at the Open Science Framework (for access see Index of Supplementary Materials below). Open Data and Open Analysis comprise the data file (txt file, tab separated), the jamovi files, the JASP file, and the additional $\mathrm{R}$ script which allow for the reproduction of all analyses reported in the paper as well as access to some extra results. Open Material comprise math anxiety (AMAS) and teaching attitudes (enjoyment and ease of teaching math) in English, German and French.

\section{Index of Supplementary Materials}

Artemenko, C., Masson, N., Georges, C., Nuerk, H.-C., \& Cipora, K. (2021). Supplementary materials to "Not all elementary school teachers are scared of math" [Data, code, and materials]. OSF. https://osf.io/w2e9j/

Journal of Numerical Cognition. (Ed.). (2021). Supplementary materials to "Not all elementary school teachers are scared of math" [Open peer-review]. PsychOpen GOLD. https://doi.org/10.23668/psycharchives.5227

\section{References}

Ashcraft, M. H. (2002). Math anxiety: Personal, educational, and cognitive consequences. Current Directions in Psychological Science, 11(5), 181-185. https://doi.org/10.1111/1467-8721.00196

Beilock, S. L., Gunderson, E. A., Ramirez, G., \& Levine, S. C. (2010). Female teachers' math anxiety affects girls' math achievement. Proceedings of the National Academy of Sciences of the United States of America, 107(5), 1860-1863. https://doi.org/10.1073/pnas.0910967107

Brady, P., \& Bowd, A. (2005). Mathematics anxiety, prior experience and confidence to teach mathematics among pre-service education students. Teachers and Teaching: Theory and Practice, 11(1), 37-46. https://doi.org/10.1080/1354060042000337084

Bursal, M., \& Paznokas, L. (2006). Mathematics anxiety and preservice elementary teachers' confidence to teach mathematics and science. School Science and Mathematics, 106(4), 173-180. https://doi.org/10.1111/j.1949-8594.2006.tb18073.x

Çatlioğlu, H., Birgin, O., Coştu, S., \& Gürbüz, R. (2009). The level of mathematics anxiety among pre-service elementary school teachers. Procedia-Social and Behavioral Sciences, 1(1), 1578-1581. https://doi.org/10.1016/j.sbspro.2009.01.277

Çatlioğlu, H., Gürbüz, R., \& Birgin, O. (2014). Do pre-service elementary school teachers still have mathematics anxiety? Some factors and correlates. Bolema-Mathematics Education Bulletin, 28(48), 110-127. https://doi.org/10.1590/1980-4415v28n48a06

Caviola, S., Primi, C., Chiesi, F., \& Mammarella, I. C. (2017). Psychometric properties of the Abbreviated Math Anxiety Scale (AMAS) in Italian primary school children. Learning and Individual Differences, 55, 174-182. https://doi.org/10.1016/j.lindif.2017.03.006

Cipora, K., Artemenko, C., \& Nuerk, H.-C. (2019). Different ways to measure math anxiety. In I. Mammarella, S. Caviola, \& A. Dokwer (Eds.), Mathematics anxiety: What is known and what is still to be understood (pp. 20-41). https://doi.org/10.1080/09697250020034788

Cipora, K., Soltanlou, M., Reips, U. D., \& Nuerk, H.-C. (2019). The SNARC and MARC effects measured online: Large-scale assessment methods in flexible cognitive effects. Behavior Research Methods, 51, 1676-1692. https://doi.org/10.3758/s13428-019-01213-5

Cipora, K., Szczygiel, M., Willmes, K., \& Nuerk, H.-C. (2015). Math anxiety assessment with the Abbreviated Math Anxiety Scale: Applicability and usefulness: Insights from the polish adaptation. Frontiers in Psychology, 6, Article 1833. https://doi.org/10.3389/fpsyg.2015.01833

Cipora, K., Willmes, K., Szwarc, A., \& Nuerk, H.-C. (2018). Norms and validation of the online and paper-and-pencil versions of the Abbreviated Math Anxiety Scale (AMAS) for Polish adolescents and adults. fournal of Numerical Cognition, 3(3), 667-693. https://doi.org/10.5964/jnc.v3i3.121

Dietrich, J. F., Huber, S., Moeller, K., \& Klein, E. (2015). The influence of math anxiety on symbolic and non-symbolic magnitude processing. Frontiers in Psychology, 6, Article 1621. https://doi.org/10.3389/fpsyg.2015.01621

Dowker, A., Sarkar, A., \& Looi, C. Y. (2016). Mathematics anxiety: What have we learned in 60 years? Frontiers in Psychology, 7, Article 508. https://doi.org/10.3389/fpsyg.2016.00508

Faulkenberry, T. J., Ly, A., \& Wagenmakers, E.-J. (2020). Bayesian inference in numerical cognition: A tutorial using JASP. Journal of Numerical Cognition, 6(2), 231-259. https://doi.org/10.5964/jnc.v6i2.288 
Ganley, C. M., Schoen, R. C., LaVenia, M., \& Tazaz, A. M. (2019). The construct validation of the math anxiety scale for teachers. AERA Open, 5(1), Article 233285841983970. https://doi.org/10.1177/2332858419839702

Gresham, G. (2007). A study of mathematics anxiety in pre-service teachers. Early Childhood Education fournal, 35(2), 181-188. https://doi.org/10.1007/s10643-007-0174-7

Gresham, G. (2008). Mathematics anxiety and mathematics teacher efficacy in elementary pre-service teachers. Teaching Education, 19(3), 171-184. https://doi.org/10.1080/10476210802250133

Gresham, G. (2018). Preservice to inservice: Does mathematics anxiety change with teaching experience? fournal of Teacher Education, 69(1), 90-107. https://doi.org/10.1177/0022487117702580

Hadley, K., \& Dorward, J. (2011). The relationship among elementary teachers' mathematics anxiety, mathematics instructional practices, and student mathematics achievement. fournal of Curriculum \& Instruction, 5(2), 27-44. https://doi.org/10.3776/joci

Harper, N. W., \& Daane, C. J. (1998). Causes and reduction of math anxiety in preservice elementary teachers. Action in Teacher Education, 19(4), 29-38. https://doi.org/10.1080/01626620.1998.10462889

Hembree, R. (1990). The nature, effects, and relief of mathematics anxiety. fournal for Research in Mathematics Education, 21(1), 33-46. https://doi.org/10.2307/749455

Hohol, M., Woloszyn, K., Nuerk, H.-C., \& Cipora, K. (2018). A large-scale survey on finger counting routines, their temporal stability and flexibility in educated adults. Peerf, 6, Article e5878. https://doi.org/10.7717/peerj.5878

Hopko, D., Mahadevan, R., Bare, R., \& Hunt, M. (2003). The Abbreviated Math Anxiety Scale (AMAS): Construction, validity, and reliability. Assessment, 10(2), 178-182. https://doi.org/10.1177/1073191103010002008

Hughes, P. T. (2016). The relationship of mathematics anxiety, mathematical beliefs, and instructional practices of elementary school teachers (Doctoral dissertation, Georgia State University, Atlanta, GA, USA). Retrieved from https://scholarworks.gsu.edu/mse_diss/21

Hughes, P. T., Swars Auslander, S., Stinson, D. W., \& Fortner, C. K. (2019). Elementary teachers' mathematical beliefs and mathematics anxiety: How do they shape instructional practices? School Science and Mathematics, 119(4), 213-222. https://doi.org/10.1111/ssm.12329

Hunt, T. E., \& Sari, M. H. (2019). An English version of the mathematics teaching anxiety scale. International fournal of Assessment Tools in Education, 6(3), 436-443. https://doi.org/10.21449/ijate.615640

Isiksal, M., Curran, J. M., Koc, Y., \& Askun, C. S. (2009). Mathematics anxiety and mathematical self-concept: Considerations in preparing elementary-school teachers. Social Behavior and Personality, 37(5), 631-644. https://doi.org/10.2224/sbp.2009.37.5.631

Jaggernauth, S., \& Jameson-Charles, M. (2015). Primary teacher mathematics anxiety, teacher efficacy and mathematics avoidance. In M. Carmo (Ed.), Education applications and developments (Advances in Education and Educational Trends, Vol. 1., pp. 45-58). Lisbon, Portugal: Science Press.

Jeffreys, H. (1961). Theory of probability (3rd ed.). New York, NY, USA: Oxford University Press.

Kaufmann, L., Nuerk, H.-C., Graf, M., Krinzinger, H., Delazer, M., \& Willmes, K. (2009). TEDI-MATH. Test zur Erfassung numerischrechnerischer Fertigkeiten vom Kindergarten bis zur 3. Klasse. Göttingen, Germany: Huber.

Kelly, W. P., \& Tomhave, W. K. (1985). A study of math anxiety/math avoidance in preservice elementary teachers. The Arithmetic Teacher, 32(5), 51-53. https://doi.org/10.5951/AT.32.5.0051

Krinzinger, H., Kaufmann, L., \& Willmes, K. (2009). Math anxiety and math ability in early primary school years. fournal of Psychoeducational Assessment, 27(3), 206-225. https://doi.org/10.1177/0734282908330583

Lee, M., \& Wagenmakers, E.-J. (2013). Bayesian modeling for cognitive science: A practical course. Cambridge, United Kingdom: Cambridge University Press.

Leiner, D. J. (2014). SoSci Survey (Version 3.1.06) [Computer software]. Available from https://www.soscisurvey.de

Ma, X. (1999). A meta-analysis of the relationship between anxiety toward mathematics and achievement in mathematics. fournal for Research in Mathematics Education, 30(5), 520-540.

Malinsky, M., Ross, A., Pannells, T., \& McJunkin, M. (2006). Math anxiety in pre-service elementary school teachers. Education, 127(2), 274-279.

Maloney, E. A. (2016). Math anxiety: Causes, consequences, and remediation. In K. R. Wentzel \& D. B. Miele (Eds.), Handbook of motivation at school (2nd ed., pp. 223-408). https://doi.org/10.4324/9781315773384

Maloney, E. A., \& Beilock, S. L. (2012). Math anxiety: Who has it, why it develops, and how to guard against it. Trends in Cognitive Sciences, 16(8), 404-406. https://doi.org/10.1016/j.tics.2012.06.008 
Moeller, K., Fischer, U., Cress, U., \& Nuerk, H.-C. (2012). Diagnostics and intervention in developmental dyscalculia: Current issues and novel perspectives. In Z. Breznitz, O. Rubinsten, V. Molfese, \& D. Molfese (Eds.), Reading, writing, mathematics and the developing brain: Listening to many voices (pp. 233-275). https://doi.org/10.1007/978-94-007-4086-0_14

Namkung, J. M., Peng, P., \& Lin, X. (2019). The relation between mathematics anxiety and mathematics performance among schoolaged students: A meta-analysis. Review of Educational Research, 89(3), 459-496. https://doi.org/10.3102/0034654319843494

Olson, A. M., \& Stoehr, K. J. (2019). From numbers to narratives: Preservice teachers experiences' with mathematics anxiety and mathematics teaching anxiety. School Science and Mathematics, 119(2), 72-82. https://doi.org/10.1111/ssm.12320

Peker, M. (2009). The use of expanded microteaching for reducing pre-service teachers' teaching anxiety about mathematics. Scientific Research and Essays, 4(9), 872-880.

Peker, M., \& Ertekin, E. (2011). The relationship between mathematics teaching anxiety and mathematics anxiety. New Educational Review, 23(1), 213-226. https://doi.org/10.12973/ejmste/75284

Porsch, R. (2017). Mathematik als Pflichtfach in der Primarstufenlehrerausbildung. Mathematikangst, Enthusiasmus und Gründe der Schwerpunktwahl angehender Grundschullehrkräfte. Lehrerbildung Auf Dem Prüfstand, 10, 104-124.

Primi, C., Busdraghi, C., Tomasetto, C., Morsanyi, K., \& Chiesi, F. (2014). Measuring math anxiety in Italian college and high school students: Validity, reliability and gender invariance of the Abbreviated Math Anxiety Scale (AMAS). Learning and Individual Differences, 34, 51-56. https://doi.org/10.1016/j.lindif.2014.05.012

Rahayu, L. P., Mustadi, A., \& Sarjiman, P. (2019). An investigation on pre-service elementary school teachers' mathematics anxiety. Al-fabar: Jurnal Pendidikan Matematika, 10(1), 111-124. https://doi.org/10.24042/ajpm.v10i1.4165

Ramirez, G., Gunderson, E. A., Levine, S. C., \& Beilock, S. L. (2013). Math anxiety, working memory, and math achievement in early elementary school. Journal of Cognition and Development, 14(2), 187-202. https://doi.org/10.1080/15248372.2012.664593

Ramirez, G., Hooper, S. Y., Kersting, N. B., Ferguson, R., \& Yeager, D. (2018). Teacher math anxiety relates to adolescent students' math achievement. AERA Open, 4(1), 1-13. https://doi.org/10.1177/2332858418756052

R Core Team (2018). R: A Language and Environment for Statistical Computing. R Foundation for Statistical Computing. https://www.r-project.org/

Reips, U.-D. (2002). Standards for internet-based experimenting. Experimental Psychology, 49(4), 243-256. https://doi.org/10.1026//1618-3169.49.4.243

Richardson, F., \& Suinn, R. (1972). The mathematics anxiety rating scale: Psychometric data. fournal of Counseling Psychology, 18(6), 6-9. https://doi.org/10.1037/h0033456

Sloan, T. R. (2010). A quantitative and qualitative study of math anxiety among preservice teachers. Educational Forum, 74(3), 242-256. https://doi.org/10.1080/00131725.2010.483909

Suárez-Pellicioni, M., Núñez-Peña, M. I., \& Colomé, À. (2016). Math anxiety: A review of its cognitive consequences, psychophysiological correlates, and brain bases. Cognitive, Affective, \& Behavioral Neuroscience, 16, 3-22. https://doi.org/10.3758/s13415-015-0370-7

Swars, S. L., Daane, C. J., \& Giesen, J. (2006). Mathematics anxiety and mathematics teacher efficacy: What is the relationship in elementary preservice teachers? School Science and Mathematics, 106(7), 306-315. https://doi.org/10.1111/j.1949-8594.2006.tb17921.x

Szczygieł, M., \& Cipora, K. (2016). Lęk przed matematyką przyszłych nauczycieli edukacji przedszkolnej i wczesnoszkolnej. Jak uczyć kiedy sama się boję? (Maths anxiety among future pre-service elementary school teachers: How to teach when I am anxious as well?). Problemy Wczesnej Edukacji/Issues in Early Education, 2(33), 89-101. https://doi.org/10.5604/01.3001.0009.4827

Uysal, F., \& Dede, Y. (2016). Mathematics anxiety and beliefs of Turkish pre-service elementary teachers. EURASIA fournal of Mathematics, Science and Technology Education, 12(8), 2171-2186. https://doi.org/10.12973/eurasia.2016.1418a

Vahedi, S., \& Farrokhi, F. (2011). A confirmatory factor analysis of the tructure of Abbreviated Math Anxiety Scale. Iranian fournal of Psychiatry, 6(2), 47-53.

Vinson, B. M. C. (2001). A comparison of preservice teachers' mathematics anxiety before and after a methods class emphasizing manipulatives. Early Childhood Education fournal, 29(2), 89-94. https://doi.org/10.1023/A:1012568711257

Wang, Z., Lukowski, S. L., Hart, S. A., Lyons, I. M., Thompson, L. A., Kovas, Y., . . Petrill, S. A. (2015). Is math anxiety always bad for math learning? The role of math motivation. Psychological Science, 26(12), 1863-1876. https://doi.org/10.1177/0956797615602471

Wood, E. F. (1988). Math anxiety and elementary teachers: What does research tell us? For the Learning of Mathematics, 8(1), 8-13.

Wu, S. S., Barth, M., Amin, H., Malcarne, V., \& Menon, V. (2012). Math anxiety in second and third graders and its relation to mathematics achievement. Frontiers in Psychology, 3, Article 162. https://doi.org/10.3389/fpsyg.2012.00162 
Zhang, J., Zhao, N., \& Kong, Q. P. (2019). The relationship between math anxiety and math performance: A meta-analytic investigation. Frontiers in Psychology, 10, Article 1613. https://doi.org/10.3389/fpsyg.2019.01613

\section{Appendix}

Table A1

Descriptive Data for Math Anxiety and Teaching Attitudes of Male Elementary School Teachers

\begin{tabular}{|c|c|c|c|c|c|}
\hline Group & & & $N$ & $M$ & $S D$ \\
\hline \multicolumn{6}{|c|}{ Math Anxiety } \\
\hline \multicolumn{6}{|l|}{ Teachers } \\
\hline Yes & & & 35 & 15.54 & 5.29 \\
\hline No & & & 251 & 16.6 & 6.79 \\
\hline \multicolumn{6}{|c|}{ Math Anxiety of Teachers } \\
\hline \multicolumn{6}{|l|}{ Specialization } \\
\hline \multirow[t]{2}{*}{ Yes } & Experience & Pre-service & 20 & 15.15 & 5.28 \\
\hline & & In-service & 4 & 15.50 & 4.20 \\
\hline \multirow[t]{2}{*}{ No } & Experience & Pre-service & 7 & 16.29 & 5.59 \\
\hline & & In-service & 4 & 16.25 & 7.54 \\
\hline \multicolumn{6}{|c|}{ Enjoyment of Teaching Math ${ }^{\mathrm{a}}$} \\
\hline \multicolumn{6}{|l|}{ Specialization } \\
\hline Yes & & & 21 & 4.33 & 0.48 \\
\hline No & & & 10 & 4.1 & 0.74 \\
\hline \multicolumn{6}{|l|}{ Experience } \\
\hline Pre-service & & & 23 & 4.26 & 0.54 \\
\hline In-service & & & 8 & 4.25 & 0.71 \\
\hline \multicolumn{6}{|c|}{ Ease of Teaching Math ${ }^{a}$} \\
\hline \multicolumn{6}{|l|}{ Specialization } \\
\hline Yes & & & 21 & 4.19 & 0.68 \\
\hline No & & & 10 & 3.6 & 0.97 \\
\hline \multicolumn{6}{|l|}{ Experience } \\
\hline Pre-service & & & 23 & 4.13 & 0.76 \\
\hline In-service & & & 8 & 3.63 & 0.92 \\
\hline
\end{tabular}

${ }^{a}$ For the analyses of teaching attitudes, elementary school teachers who selected the option "not yet taught" were excluded $(n=4)$. 
Table A2

Results for the Subscales of the AMAS for Female Teachers versus the Reference Sample of Female Students and for Female versus Male Teachers

\begin{tabular}{|c|c|c|c|c|c|c|c|c|c|c|}
\hline Group & & $N$ & $M$ & $S D$ & $t$ & $d f$ & $p$ & $d$ & $B F_{10}$ & $B F_{01}$ \\
\hline \multicolumn{11}{|c|}{ Math Anxiety } \\
\hline \multicolumn{11}{|c|}{ Learning Math Anxiety } \\
\hline \multirow[t]{2}{*}{ Teachers (Female) } & Yes & 223 & 8.48 & 3.67 & 3.04 & 818 & .002 & 0.24 & 7.75 & \\
\hline & No & 597 & 7.68 & 3.26 & & & & & & \\
\hline \multicolumn{11}{|c|}{ Math Evaluation Anxiety } \\
\hline \multirow[t]{2}{*}{ Teachers (Female) } & Yes & 223 & 12.37 & 4.42 & 1.24 & 818 & .214 & 0.10 & 0.19 & 5.36 \\
\hline & No & 597 & 11.98 & 3.93 & & & & & & \\
\hline \multicolumn{11}{|c|}{ Math Anxiety of Teachers } \\
\hline \multicolumn{11}{|c|}{ Learning math anxiety } \\
\hline \multirow[t]{2}{*}{ Gender } & Female & 223 & 8.48 & 3.67 & 2.90 & 256 & .004 & 0.53 & 8.41 & \\
\hline & Male & 35 & 6.63 & 2.22 & & & & & & \\
\hline \multicolumn{11}{|c|}{ Math evaluation anxiety } \\
\hline \multirow[t]{2}{*}{ Gender } & Female & 223 & 12.37 & 4.42 & 4.40 & 256 & $<.001$ & 0.80 & $>100$ & \\
\hline & Male & 35 & 8.91 & 3.60 & & & & & & \\
\hline
\end{tabular}

Note. $B F_{10}$-Bayes factor in favor of the alternative hypothesis (evidence for a difference); $B F_{01}-$ Bayes factor in favor of the null hypothesis (evidence for no difference) is reported when no difference was found $\left(p>.05 ; B F_{10}<1\right)$ for simplification of interpretation, whereby $B F_{01}=1 / B F_{10}$.

\section{Table A3}

Results for the Subscales of the AMAS for Specialization and Experience in Female Elementary School Teachers.

\begin{tabular}{|c|c|c|c|c|c|c|c|c|c|c|}
\hline \multirow{2}{*}{$\begin{array}{l}\text { Group } \\
\text { Descriptives }\end{array}$} & \multicolumn{5}{|c|}{ Learning Math Anxiety } & \multicolumn{5}{|c|}{ Math Evaluation Anxiety } \\
\hline & $N$ & $M$ & $S D$ & & & $N$ & $M$ & $S D$ & & \\
\hline \multicolumn{11}{|l|}{ Specialization } \\
\hline Yes & 129 & 7.55 & 2.96 & & & 129 & 11.48 & 4.37 & & \\
\hline No & 94 & 9.76 & 4.16 & & & 94 & 13.60 & 4.22 & & \\
\hline \multicolumn{11}{|l|}{ Experience } \\
\hline Pre-service & 163 & 8.39 & 3.60 & & & 163 & 12.49 & 4.51 & & \\
\hline In-service & 60 & 8.72 & 3.88 & & & 60 & 12.07 & 4.21 & & \\
\hline ANOVA & $\boldsymbol{F}$ & $d f$ & $p$ & $\eta_{\mathrm{p}}^{2}$ & & $F$ & $d f$ & $p$ & $\eta_{\mathrm{p}}^{2}$ & \\
\hline Specialization & 18.11 & 1,219 & $<.001$ & 0.08 & & 9.38 & 1,219 & .002 & 0.04 & \\
\hline Experience & 0.96 & 1,219 & .328 & 0.00 & & 0.17 & 1,219 & .678 & 0.00 & \\
\hline Interaction specialization $\times$ experience & 0.13 & 1,219 & .718 & 0.00 & & 0.12 & 1,219 & .902 & 0.00 & \\
\hline Bayesian ANOVA: Models & $P(M)$ & $P(M /$ data $)$ & $B F_{M}$ & $B F_{10}$ & Error \% & $P(M)$ & $P(M \mid$ data $)$ & $B F_{M}$ & $B F_{10}$ & Error \% \\
\hline Null model & 0.2 & 0.00 & 0.00 & 1.00 & & 0.2 & 0.01 & 0.05 & 1.00 & \\
\hline Specialization & 0.2 & 0.78 & 13.83 & $>100$ & 0.00 & 0.2 & 0.81 & 16.77 & 62.23 & 0.00 \\
\hline Specialization + experience & 0.2 & 0.18 & 0.89 & $>100$ & 1.80 & 0.2 & 0.14 & 0.67 & 11.08 & 0.94 \\
\hline Specialization + experience + interaction & 0.2 & 0.04 & 0.18 & $>100$ & 1.97 & 0.2 & 0.03 & 0.14 & 2.57 & 1.34 \\
\hline Experience & 0.2 & 0.00 & 0.00 & 0.19 & 0.00 & 0.2 & 0.00 & 0.01 & 0.20 & 0.00 \\
\hline Bayesian ANOVA: Effects & $P($ incl $)$ & $P($ incl $\mid$ data $)$ & $B F_{\text {incl }}$ & $B F_{\text {excl }}$ & & $P($ incl $)$ & $P($ incl $\mid$ data $)$ & $B F_{\text {incl }}$ & $B F_{\text {excl }}$ & \\
\hline Specialization & 0.4 & 0.96 & $>100$ & 0.00 & & 0.4 & 0.95 & 61.30 & 0.02 & \\
\hline Experience & 0.4 & 0.18 & 0.23 & 3.95 & & 0.4 & 0.15 & 0.18 & 5.60 & \\
\hline Interaction specialization $\times$ experience & 0.2 & 0.04 & 0.23 & 4.18 & & 0.2 & 0.03 & 0.23 & 4.32 & \\
\hline
\end{tabular}

Note. The effect-based analyses (lower part of the table) compares models that contain the effect to equivalent models stripped of the effect (analysis suggested by Sebastiaan Mathôt). 
Table A4

Math Anxiety Results for Specialization Separately for German Teachers (During Elementary School Teacher Education) and Belgian Teachers (During Secondary School).

\begin{tabular}{|c|c|c|c|c|c|c|c|c|c|c|}
\hline \multirow{2}{*}{$\frac{\text { Group }}{\text { Descriptives }}$} & \multicolumn{5}{|c|}{ German Teachers (Female) } & \multicolumn{5}{|c|}{ Belgian Teachers (Female) } \\
\hline & $N$ & $M$ & $S D$ & & & $N$ & $M$ & $S D$ & & \\
\hline \multicolumn{11}{|l|}{ Specialization } \\
\hline Yes & 64 & 18.59 & 5.86 & & & 65 & 19.46 & 7.19 & & \\
\hline No & 52 & 23.21 & 6.88 & & & 42 & 23.52 & 8.18 & & \\
\hline \multicolumn{11}{|l|}{ Experience } \\
\hline Pre-service & 92 & 20.73 & 6.81 & & & 71 & 21.07 & 7.73 & & \\
\hline In-service & 24 & 20.42 & 6.47 & & & 36 & 21.03 & 8.09 & & \\
\hline ANOVA & $\boldsymbol{F}$ & $d f$ & $p$ & $\eta_{\mathrm{p}}^{2}$ & & $\boldsymbol{F}$ & $d f$ & $p$ & $\eta_{\mathrm{p}}^{2}$ & \\
\hline Specialization & 10.66 & 1,112 & .001 & 0.09 & & 6.20 & 1,103 & .014 & 0.06 & \\
\hline Experience & 0.02 & 1,112 & .886 & 0.00 & & 0.01 & 1,103 & .939 & 0.00 & \\
\hline Interaction specialization $\times$ experience & 0.10 & 1,112 & .756 & 0.00 & & 0.00 & 1,103 & .949 & 0.00 & \\
\hline Bayesian ANOVA: Models & $P(M)$ & $P(M /$ data $)$ & $B F_{M}$ & $B F_{10}$ & Error \% & $P(M)$ & $P(M \mid$ data $)$ & $B F_{M}$ & $B F_{10}$ & Error \% \\
\hline Null model & 0.2 & 0.01 & 0.02 & 1.00 & & 0.2 & 0.13 & 0.59 & 1.00 & \\
\hline Specialization & 0.2 & 0.76 & 12.50 & $>100$ & 0.00 & 0.2 & 0.66 & 7.67 & 5.09 & 0.00 \\
\hline Specialization + experience & 0.2 & 0.18 & 0.87 & 33.88 & 0.87 & 0.2 & 0.14 & 0.65 & 1.08 & 1.65 \\
\hline Specialization + experience + interaction & 0.2 & 0.06 & 0.24 & 10.72 & 1.19 & 0.2 & 0.05 & 0.19 & 0.36 & 12.92 \\
\hline Experience & 0.2 & 0.00 & 0.01 & 0.24 & 0.02 & 0.2 & 0.03 & 0.11 & 0.22 & 0.03 \\
\hline Bayesian ANOVA: Effects & $P($ incl $)$ & $P($ incl $\mid$ data $)$ & $B F_{i n c l}$ & $B F_{\text {excl }}$ & & $P($ incl $)$ & $P($ incl $\mid$ data $)$ & $B F_{\text {incl }}$ & $B F_{\text {excl }}$ & \\
\hline Specialization & 0.4 & 0.94 & $>100$ & 0.01 & & 0.4 & 0.80 & 5.08 & 0.20 & \\
\hline Experience & 0.4 & 0.18 & 0.24 & 4.23 & & 0.4 & 0.17 & 0.21 & 4.70 & \\
\hline Interaction specialization $\times$ experience & 0.2 & 0.06 & 0.32 & 3.16 & & 0.2 & 0.05 & 0.33 & 3.01 & \\
\hline
\end{tabular}

Note. The effect-based analyses (lower part of the table) compares models that contain the effect to equivalent models stripped of the effect (analysis suggested by Sebastiaan Mathôt).

\section{Table A5}

Teaching Attitude Results Separately for German Teachers and Belgian Teachers (Ordinal Logistic Regression)

\begin{tabular}{|c|c|c|c|c|c|c|c|c|c|c|c|c|c|}
\hline \multirow{2}{*}{\multicolumn{2}{|c|}{$\frac{\text { Predictor }}{\text { Enjoyment of Teaching Math }}$}} & \multicolumn{6}{|c|}{ German Teachers (Female) } & \multicolumn{6}{|c|}{ Belgian Teachers (Female) } \\
\hline & & \multirow{2}{*}{$\begin{array}{c}\text { Estimate } \\
-0.12\end{array}$} & \multirow{2}{*}{$\begin{array}{c}S E \\
0.04\end{array}$} & \multirow{2}{*}{$\begin{array}{c}Z \\
-2.92\end{array}$} & \multirow{2}{*}{$\begin{array}{l}p \\
.004\end{array}$} & \multicolumn{2}{|c|}{ Odds Ratio [95\% CI] } & \multirow{2}{*}{$\begin{array}{c}\text { Estimate } \\
-0.13\end{array}$} & \multirow{2}{*}{$\begin{array}{c}S E \\
0.03\end{array}$} & \multirow{2}{*}{$\begin{array}{c}Z \\
-4.61\end{array}$} & \multirow{2}{*}{$\begin{aligned} & \boldsymbol{p} \\
< & .001\end{aligned}$} & \multicolumn{2}{|c|}{ Odds Ratio [95\% CI } \\
\hline Math anxiety & & & & & & 0.89 & {$[0.82,0.96]$} & & & & & 0.88 & {$[0.83,0.93]$} \\
\hline Specialization & Yes vs. no & 1.38 & 0.53 & 2.59 & .010 & 3.96 & {$[1.41,11.50]$} & 1.01 & 0.40 & 2.55 & .011 & 2.75 & {$[1.27,6.05]$} \\
\hline Experience & In-vs. pre-service & -0.40 & 0.52 & -0.77 & .441 & 0.67 & {$[0.24,1.90]$} & 0.06 & 0.40 & 0.14 & .890 & 1.06 & {$[0.48,2.35]$} \\
\hline \multicolumn{2}{|c|}{ Ease of Teaching Math } & Estimate & $S E$ & $Z$ & $p$ & \multicolumn{2}{|c|}{ Odds Ratio [95\% CI] } & Estimate & $S E$ & $Z$ & $p$ & \multicolumn{2}{|c|}{ Odds Ratio $[95 \% \mathrm{CI}]$} \\
\hline Math anxiety & & -0.13 & 0.04 & -3.46 & $<.001$ & 0.88 & {$[0.81,0.94]$} & -0.12 & 0.03 & -4.56 & $<.001$ & 0.88 & {$[0.84,0.93]$} \\
\hline Specialization & Yes vs. no & 1.42 & 0.52 & 2.71 & .007 & 4.14 & {$[1.51,11.93]$} & 0.85 & 0.40 & 2.10 & .036 & 2.33 & {$[1.06,5.19]$} \\
\hline Experience & In- vs. pre-service & -0.22 & 0.51 & -0.43 & .667 & 0.80 & {$[0.29,2.19]$} & 0.77 & 0.40 & 1.91 & .056 & 2.16 & {$[0.99,4.82]$} \\
\hline
\end{tabular}

Note. Model characteristics for German teachers: enjoyment of teaching math, AIC $=161.13, \mathrm{BIC}=177.35, R_{M c F}^{2}=.13$, and ease of teaching math, AIC

$=167.95, \mathrm{BIC}=181.77, R_{M C F}^{2}=.15$. Model characteristics for Belgian teachers: enjoyment of teaching math, $\mathrm{AIC}=240.58, \mathrm{BIC}=259.29, R_{M c F}^{2}=.14$, and ease of teaching math, $\mathrm{AIC}=252.30, \mathrm{BIC}=271.01, R_{M c F}^{2}=.13$.

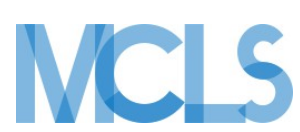

Journal of Numerical Cognition (JNC) is an official journal of the Mathematical Cognition and Learning Society (MCLS).

\section{(P) leibniz-psychology.org}

PsychOpen GOLD is a publishing service by Leibniz Institute for Psychology (ZPID), Germany. 